The International Journal Of Engineering And Science (IJES)

|| Volume || 6 || Issue || 3 || Pages || PP 122-128 || 2017 ||

ISSN (e): $2319-1813$ ISSN (p): $2319-1805$

\title{
An Analysis of the E-Agriculture Research Field Between 2005 and 2015
}

\author{
Edison Wazoel Lubua \\ Institute of Accountancy Arusha P. O. Box 2798, Arusha, Tanzania
}

\begin{abstract}
In this study, research papers featured in the following peer reviewed journals and conference were analysed: The African Journal of Information Systems (AJIS), The African Journal of Information and Communication Techn ology (AJICT), the Electronic Journal of Information Systems in Developing Countries (EJISDC) and the IST-Africa Conference series. These papers are those which covered the e-government field, and they were released between 2005 and 2015 with the African context. The intention of the analysis was to establish research patterns characterising the publications in a period of 10 years. The results show the increase of published papers on e-agriculture over the years. Most of the papers were conducted in East Africa and were assessing the potential of available ICTs for agriculture. Moreover, the predominant scope of analysis was the country level, while descriptive research questions featured more. Furthermore, the most adopted research paradigm was the critical theory, and the knowledge contribution was the best practise. Lastly, the most adopted technology-object (of many papers) was the infrastructure, while the large per cent of recommendations were on planning.
\end{abstract}

Date of Submission: 02 March 2017

Date of Accepted: 27 March 2017

\section{BACKGROUND OF THE STUDY}

Human generations depend on the right information to make decisions in their day today activities (Brynjolfsson \& Mendelson, 1993). In the early years (Before 1990s) of ICT for Development, facilities such as radio, Television and prints were used to communicate information among members of the society (Lubua, 2014; Gomez, 2013). Although these facilities were better than the traditional methods for communication, they had their limitations in ensuring that the information is disseminated efficiently (Serova, 2012).

Reports show that the Information and Communication Technology for Development (ICTD) field is growing fast (Heeks, 2010; Gomez, 2013). Currently, more professions depend on ICTs for their development. This increase is partly influenced by the introduction of the internet (Bargh \& McKenna, 2004). The internet provides more rooms for enhancing the way the information is communicated among members of the society. For example, websites, blogs, social media, emails and even text messages, are part of the tools that support information dissemination among members of the society.

On the other hand, the increase of ICT uses in human activities is reflected by the growth of research activities in the area of ICTD (Gomez, 2013). In the study by Heeks (2010), the publication of research papers about Information and Communication Technology for Development (ICTD) increased by $2000 \%$ in the first decade of the $21^{\text {st }}$ century. Patra et al., (2009) commented that ICTD is in its maturity stage, as the result, it allows some of its sub-fields to emerge as the new area of research interest. One of the research areas gaining the popularity is e-agriculture. The development of the field of e-agriculture is influenced by the dynamic nature of agriculture activities (World Bank, 2011). The unpredictable nature of the climate necessitates farmers to rely on information systems to have a productive season. On the same ground, media and other organisations are using online platforms to increase efficiency in information dissemination (Olugbode, et al., 2008).

This study acknowledges the growth of the field of e-agriculture together with associated research activities. A proper study on the characteristics of research works in the area of e-agriculture is required. The basic characteristics that were studied are shown in section 2, below. Gomez (2013) conducted a similar study on ICTD, however the study do not provide a proper reflection on what is happening in e-agriculture. Moreover, the Gomez study extracted its data in journals and conferences across the world, while the current study concentrates in the African context.

\section{OBJECTIVE OF THE STUDY}

This study analysed characteristic of research works on e-agriculture, presented in conference proceedings and journals between 2005 and 2015. It seeks to know how different research papers published in journals and conferences can be used to describe the field of e-agriculture. Characteristics which are included in the analysis are the geographic distribution, the research domain covered, the scope, the nature of research questions, 
research methods, the main contribution, technology-object and the focus of recommendations. Only papers addressing e-agriculture in Africa, which featured in the IST-Africa Conference proceedings, the African Journal of Information Systems, African Journal of Information and Communication Technology and the Electronic Journal of Information Systems in Developing Countries were included.

\section{METHODOLOGY}

Data for this study were collected, analysed and reported in May 2015. Originally, it was the intention of the study to include journals and conferences based in Africa, which address e-agriculture topics. However, the study did not find any African journal or conference, specific to e-agriculture, which has an online presence before and after 2010. Therefore, the researcher was obliged to use papers on e-agriculture available on ICTD online platforms. To complement few available African platforms (with e-agriculture papers), the study included one journal hosted in China. The journal is specifically for studies conducted in developing countries (including Africa). The following journals are the source of analysed papers: the African Journal of Information Systems (AJIS), the African Journal of Information and Communication Technology (AJICT), and the Electronic Journal of Information Systems in Developing Countries (EJISDC). Other papers were extracted from the ISTAfrica conference series. Generally, many African journals are still facing the challenge of online presence, and many of those which were online, lacked coverage on e-agriculture.

The study is descriptive. It describes the characteristics of research works on e-agriculture. In the process, a closed-end questionnaire was designed to assist the data collection process. Variables of the questionnaire were adopted from the study by Gomez (2013), which analysed the ICTD trend between 2000 and 2010. The variables were the journal or conference name, the year of publication, the geographical region of focus, the research domain, the scope of analysis, the nature of research questions, the adopted research method, the adopted pragmatic stance, the technology-object of the study, and the focus of recommendations. The study used the questionnaire to extract the information from papers published in above mentioned sources. These papers featured in these journals between 2005 and 2015.

After relevant data were extracted from research papers, they were coded to the format accepted by SPSS, for analysis. The analysis produced descriptive information (per cent and frequency), which were used in decision making. Data were presented through tables and figures.

The extraction, coding and analysis process was done by the main author of this article. The author is adequately informed of the variables, methodological processes and ethics of research. The research process in this study required a good understanding of research processes, therefore, the author engaged himself in all processes to ensure that the information is reliable. Ontologically, the author tried the best he could to be objective. Therefore, the findings are not based on the author's opinions. Table 1 is a simple representation articles and their sources.

Table1: Sources of Information

\begin{tabular}{|l|l|l|l|}
\hline \multicolumn{2}{|c|}{} & Frequency & Percent \\
\hline Valid & IST Africa & 22 & 50.0 \\
\cline { 2 - 4 } & AJIS & 11 & 25.0 \\
\cline { 2 - 4 } & EJISDC & 9 & 20.5 \\
\cline { 2 - 4 } & AJICT & 2 & 4.5 \\
\cline { 2 - 4 } & Total & 44 & 100.0 \\
\hline
\end{tabular}

\section{RESULTS}

This study analysed papers on e-agriculture, published in four different platforms between 2005 and 2015. A general observation is that there is an increase of published papers in the area of e-agriculture. Particularly, 2013 published more papers than all other years; this is about $34.5 \%$ of the whole sample. It was further observed that the majority of research works published before 2008 considered e-agriculture as a subset within a paper discussing ICTD in general. Nevertheless, studies that were conducted in years beyond 2010, addressed specific areas of concern in e-agriculture. The increase of the number of papers in year after year, plus the specificity of studies observed is the sign of maturity in the field of e-agriculture.

Furthermore, about $85 \%$ of all papers were released in 2010 and beyond. However, many of these papers (54\%) were published by the IST-Africa conference; the AJIS, AJICT and EJISDC contributed the rest. Besides, authors who featured in journal publications were more affiliated to learning institutions. Papers for authors without academic affiliation featured in the conference

\subsection{Geographical Distribution}

In this study, the research papers which were analysed are those with studies conducted within Africa. Therefore, the geographical distribution included the following regions within the African continent: East Africa, Southern Africa, West Africa, North Africa, Central Africa and other parts of Africa. The results of the 
analysis report more studies (in e-agriculture) to have been conducted in East Africa (51.7\%). In the Southern part of Africa it was $21.4 \%$. The remaining part was distributed to the other part of the region. This study acknowledges the presence of many local and international journals (conferences) where authors may have opted to publish their research work instead of the selected cases. It was difficult to include such papers because of their online absence. It is because of this reason that the presented per cent may not necessarily reflect the actual trend of studies conducted in Africa on e-agriculture in different regions.

Moreover, in works that were published in both East Africa and Southern Africa, the majority of them were published in 2011, 2012 and 2013. The increase in research work (within these regions) reflects political emphasis on investing to Agriculture, advocated during this period of time. For example, Kenya used a slogan known as "Kilimo Salama - Safe Agriculture", while Tanzania used "Kilimo Kwanza-Agriculture First" to promote agriculture (Ministry of Agriculture, Food Security and Food Security and Co-operatives, 2013).

\subsection{Research Domains}

Generally, e-agriculture makes one of the domains in studies related to the field of Information Systems for Development (Gomez, 2013; Cushman \& McLean, 2008). However, this study made a further division of eagriculture to include the following sub-domains: Conceptualisation, design, development, evaluation and application of e-agriculture system(s). Results in Figure 1 reveal that about $48 \%$ of the analysed research papers belonged to the evaluation sub-domain. Moreover, $64 \%$ of studies under this sub-domain were conducted between 2011 and 2014. This information suggests that much of the e-agriculture systems in these studies were already established for use (Clain \& Myers, 1999). Therefore, researchers were eager to know the contribution of these systems to agriculture and the lives of members of the community. On the other hand, the second top discussed sub-domain was conceptualization (17.2\%). In this sub-domain, studies focused on developing the model (framework) suitable in addressing a certain agricultural problem. It is because of this reason that such studies considered technical projects for their case. Other discussed domains with their respective per cent include: Design (13.8\%), system development (10.3\%) and system application (10.3\%).

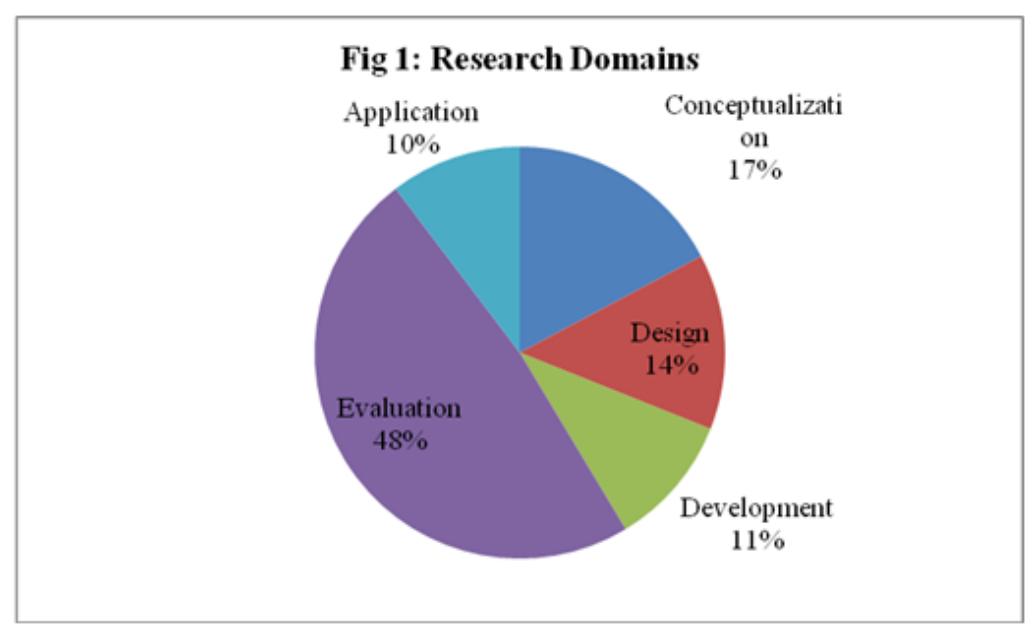

Generally, it was striking to note that about $61.5 \%$ of studies which were either on conceptualization, design or development sub-domain were reported through the IST-Africa Conference series, and many of them were reported by people without academic affiliations. The rest were reported through the AJIS, AJICT and EJISDC. It is likely that conferences offer a mechanism to accommodate works from professionals than it is a custom in journals.

\subsection{The Scope of the Analysis}

Data from extracted papers were studied to understand the level (scope) of analysis exercised by authors in the field of e-agriculture between 2005 and 2015. The analysis was according to the following level of analysis: Individual, organisation, township, country and multiple countries. Overall, the study noted the country level as the most dominant scope. According to results in Figure 2, about 34.5\% of all analysed papers were conducted at the country level. The country level was followed by district level of analysis (20.7), Individual level of analysis (20.7), multiple countries level of analysis (13.8\%), and organization level (10.3\%). Equally, the study compares with Gomez (2013) who conducted a similar study on the trend of information systems research, and found the country level analysis as the dominant scope of analysis. 


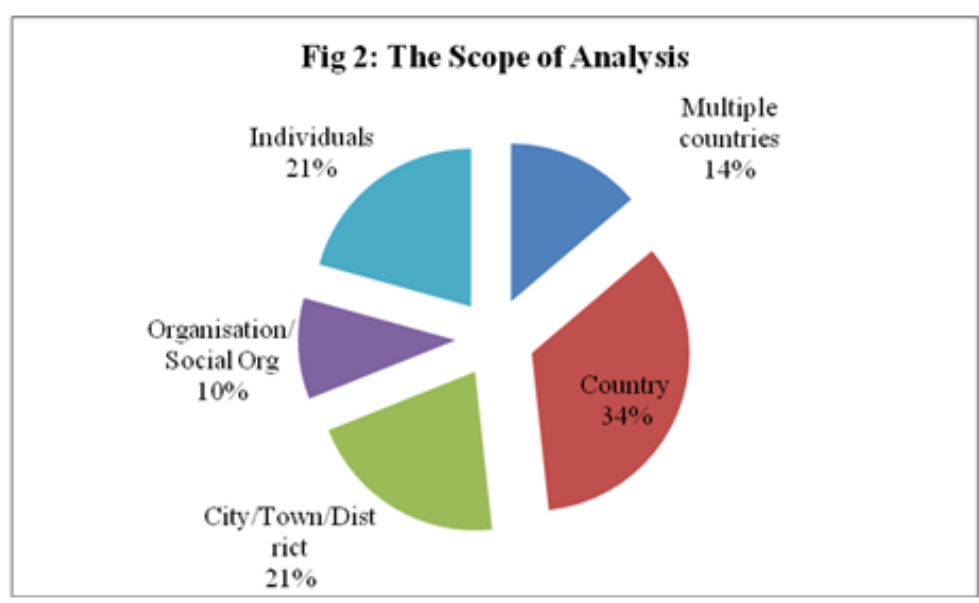

In the analysis conducted to the IST-Africa Conference papers, about $33.3 \%$ of all the papers are at the country level scope. There is a slight difference with the results from the AJIS, AJICT and EJISDC papers, where together presented $35.7 \%$. It was further observed that about $50 \%$ of analysed papers (with the country level of scope), were conducted to evaluate the status of ICT projects implemented in agriculture.

An additional analysis was conducted to know how variables of the scope of analysis are distributed across the years. Generally, studies on the country level scope are distributed throughout the years, with the year 2013 making the highest per cent $(60 \%)$. While the rest of the scope categories do not show any consistent trend, it is surprising that studies under the individual level of scope mostly appear in 2013 and 2014. This is about 66\% of all papers in this category. Moreover, all studies that were conducted at the individual level of scope were published in the IST-Africa conference. These papers were developed to discuss the design or framework of ICT projects under development.

\subsection{Nature of Research Questions}

This part of the study analysed the nature of the research question, according to the following categories: Descriptive, relational and causal. The descriptive category aims at describing observable features of the variable under study. The relationship questions, explain how variables are related, and the causal shows how the status of one variable affects the other. The analysis showed that $96.5 \%$ of studies adopted the descriptive nature of the research question. In the process, only 3.5\% of analysed studies were not clear about the nature of their research questions. Also, the dominance of descriptive studies is reported by Day \& Gomez (2013), in their study of research questions, paradigms and methods in ICT for Development.

\subsection{Research Methods and Paradigmatic Stances}

This section analyses research methods and pragmatic stances adopted by the sampled research papers. The grouping of research papers to their respective paradigm was guided by Guba's typology (Guba, 1990). The typology differentiates pragmatic stances based on their ontology, epistemology and methodology. Table 1 summarises the typology.

Table 1: Paradigmatic Stances (Guba, 1990)

\begin{tabular}{|l|l|l|l|l|}
\hline & Positivism & Post Positivism & Critical Theory & Constructivism \\
\hline Ontology & Realist & Critical Realist & Critical Realist & Relativist \\
\hline $\begin{array}{l}\text { Epistemology (Nature of } \\
\text { Relationship between } \\
\text { knower and known) }\end{array}$ & $\begin{array}{l}\text { Dualist/ } \\
\text { Objectivist }\end{array}$ & $\begin{array}{l}\text { Modified } \\
\text { Objectivist }\end{array}$ & Subjectivist & Subjectivist \\
\hline Methodology & $\begin{array}{l}\text { Experimental/ } \\
\text { Manipulative }\end{array}$ & $\begin{array}{l}\text { Modified } \\
\text { Experimental/ } \\
\text { Manipulative }\end{array}$ & $\begin{array}{l}\text { Dialogical/ } \\
\text { Transformative }\end{array}$ & Hermeneutic. dialectic \\
\hline
\end{tabular}

With reference to the typology presented in Table 1, the sample was grouped according to four stances: Positivism, Post Positivism, Critical theory and Constructivism. Accordingly, the results of the analysis showed that $34.5 \%$ of analysed papers followed the Critical Theory. The information for other paradigms is as follows: Constructivism (20.7\%), Post-Positivism (20.7\%) and Positivism (10.3\%). Also, the pragmatic stances for about $10.3 \%$ of the analysed work could not be identified. All studies which followed the Critical theory or constructivism stances were purely qualitative. Moreover, all studies which adopted mixed research methods were under Post-positivism stance. Furthermore, $60 \%$ and $40 \%$ of research papers which followed quantitative methods were under Positivism and Post-Positivism stances respectively. 


\subsection{Main Contribution to the Field}

In this section, research papers were classified based on the contribution they make to the body of knowledge. The classification was based on whether the research paper' contribution was to the best practice, field experience, policy recommendations, and theory development. Papers which were not in any of these variables were classified in a group known as "others". The results in Figure 3 suggest the best practice (44.5\%) to be the area with the most contribution in analysed papers. This is followed by theory development (37.9\%). Policy recommendations and field experience had 6.9 per cent each. Moreover, the contribution of 3.4 per cent of research works was not clear.

Fig 3: The Per cent of Aspects for the Contribution to the Field

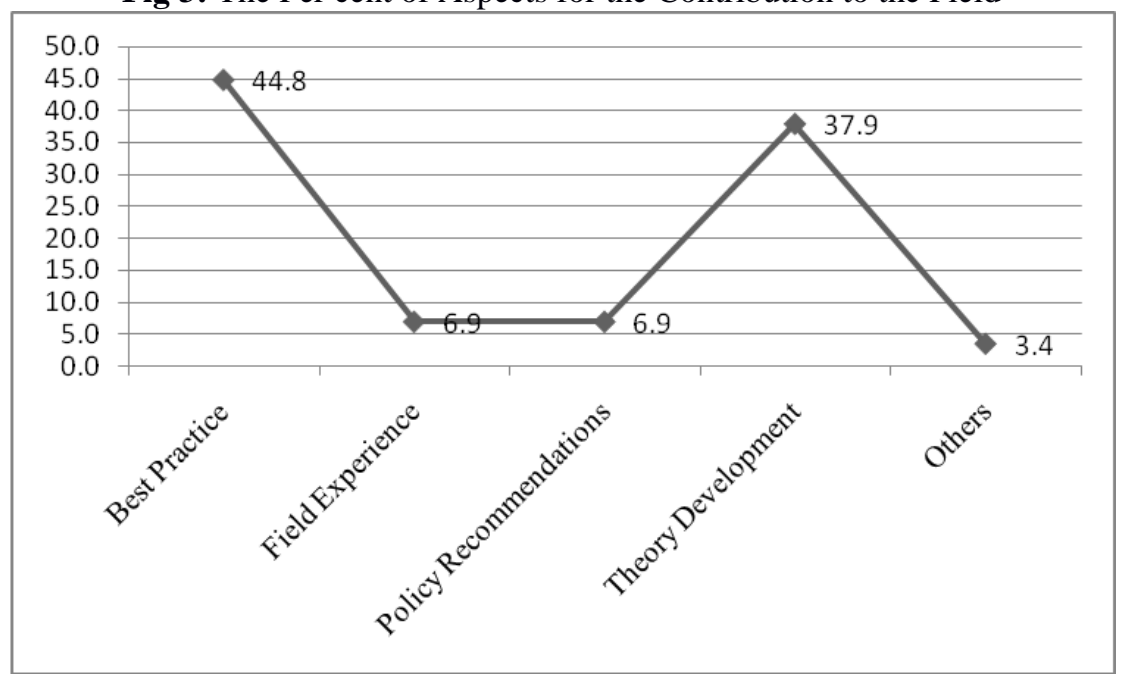

Further observations show about 54\% of research papers with their contribution on best practices to have adopted the evaluation domain discussed in section 5.2 above. This observed trend seems to have a logical link because; papers which are evaluating the already implemented programs (projects) are seeking to establish the best way to operate to improve the performance (Silver, 2006).

Moreover, it was further established that $64 \%$ of research papers with their contribution to theory development adopted either the conceptualisation, design or development domain. In this case, the main idea is that many of these studies were testing the theory or model used in early stages of project development.

\subsection{Technology Object}

The term "technology-object" is adopted from the study by Gomez (2013), who considered it as the category of technology the research is studying. The following variables were used to know the technology-object of research papers conducted between 2005 and 2015 in e-agriculture. The variables were e-business, e-capacity development, infrastructure, e-problem solving and data bank. The results in Figure 4 show that the infrastructure $(38 \%)$ is the category of technology-object addressed by most of the studies. This may have been influenced by the fact that during this period, many e-agriculture platforms were under development (or had just completed the development); therefore, it was the interest of researchers to evaluate the performance of the adopted infrastructure of the e-agriculture system. The infrastructure technology-object is closely followed by the e-problem solving (31\%) object. Figure 4 presents other categories of technology-object with their respective per cent covered by analysed studies.

Moreover, while the rest of the technology-object variables do not provide a clear trend to which they were adopted; studies that adopted the infrastructure and e-problem solving object gained more popularity between 2012 and 2014. Basically, about 75\% of these studies were conducted during this period. During this period of time, East African countries had a great political emphasis on agriculture and associated infrastructure. This may have influenced the decisions of researchers on the technology-object to adopt. 


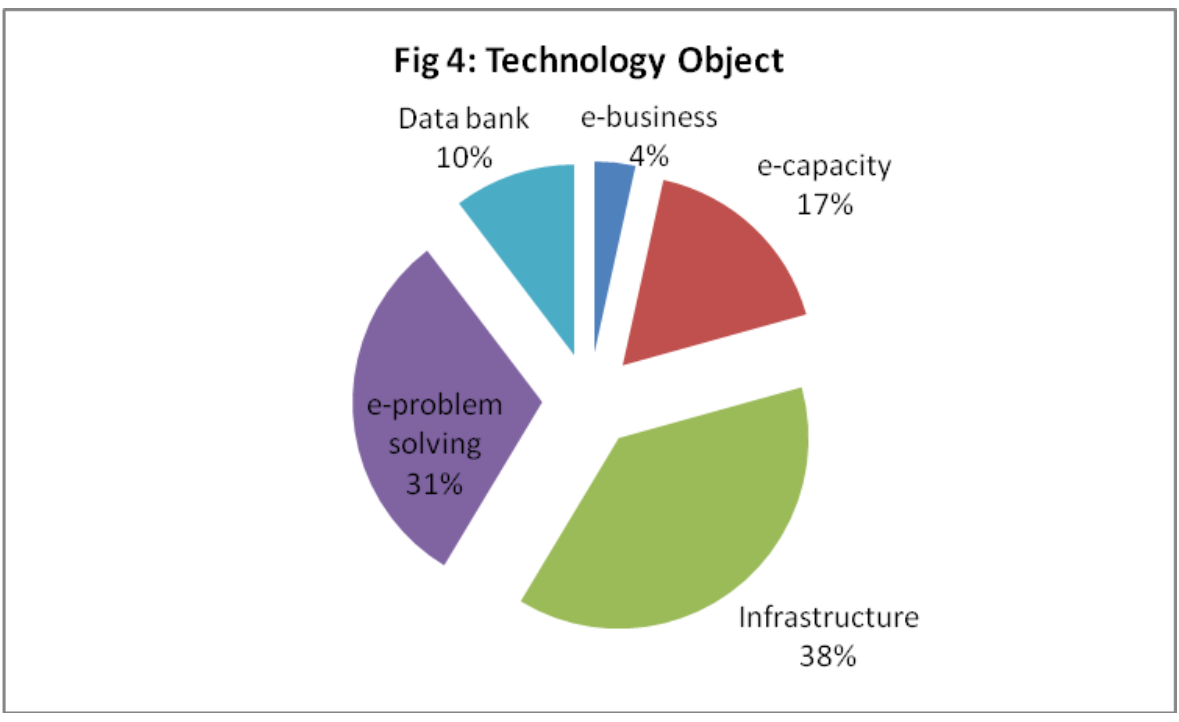

\subsection{The Focus of Recommendations}

This section of the study used the following variables to analyse the type of recommendations used by researchers between 2005 and 2015: The infrastructure, collaborations (participation), effective planning (implementation), capacity building and training, monitoring and evaluation, interface and processing design, influence (inform policy), and awareness and communication. According to results in Figure 5, many studies offered their recommendations on effective planning (31\%). Other categories of recommendations that followed include capacity building and training (24\%) and recommendations on infrastructure (21\%). This study considers these three areas as key in ensuring that e-agriculture is well adopted in African countries. Other areas of recommendations are shown in figure 5 , with their per cent.

\section{CONCLUSIONS}

This study was important because its findings enabled the researcher to know the characteristics of research on e-agriculture between 2005 and 2015. Although there is no uniform increase in publications on e-agriculture across visited platforms, it is evident that peer reviewed research papers on the subject are increasing in Africa. In some regions (For example: East Africa) the increase was a reflection of political emphasis on agriculture. Also, the fact that many studies were assessing the usefulness of ICTs in agriculture shows that: e-agriculture systems were already in place in many African countries. It was further observed that the adoption of eagriculture identified itself with individual countries than that of geographical blocks or organisation level; that is why much of the analysed papers were in the country level. Also, the contributions of most studies were on best practises, while effective planning was highly recommended for effective utilisation of e-agriculture infrastructure. Unfortunately, to many studies pragmatic stances were not clearly identified.

With these results, the study recommends the followings: The establishment of journals on e-agriculture based in Africa, ensuring the online presence of journals and conference works for publicity, a common understanding on the pragmatic stance(s) suitable for studies in e-agriculture, a continual support from political platform on supporting the integration of ICTs to agriculture.

\section{REFERENCES}

[1]. Bargh, J. \& McKenna, K. (2004). The Internet and Social Life, New York: New York University.

[2]. Brynjolfsson, E., \& Mendelson, H. (1993). Information Systems and the Organization of Modern Enterprise. Journal of Organizational Computing, 10-15.

[3]. Clain, H. \& Myers, M. (1999). Evaluating Enterpretive Field Studies in Information Systems. Management Information Systems, 23(1), pp. 67-94

[4]. Cushman, M. \& McLean, R. (2008). Exclusion, inclusion and changing the face of information systems research. Information Technology and People, pp. 213-221.

[5]. Day, S. \& Gomez, R. (2013). Research Question, Paradgm and Methods in ICT for Development: Content Analysis of Selected Literature (2000-2010). Montego Bay, s.n.

[6]. Gomez, R. (2013). The Changing Field of ICTD: Growth and Maturation of the Field. EJISDC, pp. 1-21.

[7]. Guba, E., 1990. The Paradgm Dialog. Newbury Park: Sage Publications.

[8]. Heeks, R. (2010). ICT-for-Development Research: Size and Growth. [Online] Available at: https://ict4dblog. wordpress.com/ 2010/02/08/ict-for-development-research-size-and-growth/ [Accessed 21 May 2015].

[9]. Lubua, E. (2014). E-transparency a nd Information Sharing in the Public Sector. International Journal of Computer Science and Business Informatics, 14(1), pp. 30-39.

[10]. Ministry of Agriculture, Food Security and Food Security and Cooperatives (2013). Annual Report (2012-2013), Dar Es Salaam: Government of Tanzania. 
[11]. Olugbode, M., Elbeltagi, I., Simmons, M. \& Biss, T. (2008). The Effect of Information Systems on Firm Performance and Profitability Using a Case-Study Approach. The Electronic Journal Information Systems Evaluation, 11(1), pp. 35-40.

[12]. Patra, R., Pal, J. \& Nedevschi, S. (2009). ICTD State of Union: Where have we reached and and Where are we Headed?, Doha: IEEE.

[13]. Serova, E. (2012). Enterprises Information Systems of New Generation. The Electronic Journal of Information Systems Evaluation, 15(1), pp. 116-126.

[14]. Silver, H. (2006). Evaluation Research in Education. [Online] Available at: http://www.edu.plymouth.ac.uk/resined/evaluation/ [Accessed 25 May 2015].

[15]. World Bank (2011). ICT in Agriculture, Washington, DC: World Bank. 